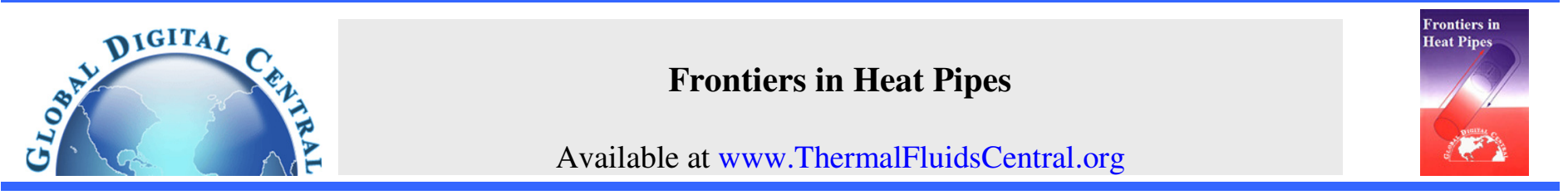

\title{
THERMAL ANALYSIS AND FLOW VISUALIZATION OF A FLAT LOOP HEAT PIPE
}

\author{
Md Monir Hossain ${ }^{\mathrm{a}}$, John Kizito ${ }^{\mathrm{b}^{*}}$ \\ ${ }^{a}$ Department of Biomedical Engineering and Mechanics, Virginia Tech, Blacksburg, VA, 24060, USA \\ ${ }^{b}$ Mechanical Engineering Department, North Carolina A\&T State University, Greensboro, NC, 27410, USA
}

\begin{abstract}
Thermal management is an important issue for electronic cooling application. Choosing an efficient cooling technique depends on thermal performance, reliability, manufacturing cost, and prospects for minimization of packaging cost. A loop heat pipe with a flat evaporator and a flat gap condenser was designed and developed to evaluate the loop performance for a range of heat load. During the study, the startup process and temperature profiles at different components of loop were compared at various heat loads. Heat transfer coefficients and the thermal resistances of the loop were also measured at these loads. In the evaporator, a disc shape copper wick was able to handle 100-watt heat load with the evaporator thermal resistance of $0.14^{\circ} \mathrm{C} / \mathrm{W}$ and heat transfer coefficient of $14.114 \mathrm{~W} / \mathrm{m}^{2}{ }^{\circ} \mathrm{C}$. To visually investigate the startup process and component performance, main structure of loop heat pipe was fabricated inside acrylic plastic block. The startup process in the vapor line, the formation of bubble inside condenser and compensation chamber during the loop heat pipe operation were visualized and explained. The visualization process helps to understand the physical phenomenon of the complete heat loop in a single frame.
\end{abstract}

Keywords: Loop heat pipe, compensation chamber, evaporator, condenser, thermal resistance

\section{INTRODUCTION}

Loop heat pipe has raised interest in thermal management of high heat generating electronic devices (Sauciuc et al., 2005). Reliability of these electronic components depends on temperature level, which is a big challenge for thermal management. A conventional cooling system is not capable of removing high heat flux from the compact electronic system. Loop heat pipe (LHP) can be an effective solution to these thermal problems. LHP is a passive device which can operate in any orientation and capable of self-starting. LHP's application gained its popularity after successful operation in space programs (Bienert W.B., 1999). Now LHP is successfully used in cooling of laptops and desktops (Kim et al., 2003). They are also used effectively for thermal management of electronic system (Singh et al., 2007). Miniature cylindrical LHP has been developed for electronic cooling applications (Maydanik et al., 2005).

Many researchers have studied the operating principle of LHP theoretically and experimentally (Launay et al., 2007). Experiments have been performed to improve the overall efficiency of LHP. Now there are diverse designs in evaporators and compensation chambers. The conventional shape of evaporator is cylindrical. But cylindrical shape needs a saddle to apply heat, which means extra components and space. For easy integration into compact electronic systems, researchers are interested in flat evaporator which leads to miniaturization of LHP. Miniaturization affects the thermal-hydraulic link between the evaporator and the compensation chamber. Flat evaporator has advantages over conventional design due to low thermal resistance and small mass of the body. Experimental investigations on LHP with flat evaporator were carried out to improve the heat transfer performance. Experiments have been performed in different operating conditions(Gai et al., 2009), with different kinds of working fluid (Liu et al., 2011) and various wick structure design (Joung et al., 2008) to achieve the optimum heat flux removal capability. But, the two-phase fluid in the loop makes the mechanism complex. Especially, it is extremely important to understand the startup and steady state operating condition in the loop at different heat load conditions (Maidanik et al., 1995). Performance of LHP can be unstable at low as well as high heat load conditions. Failure of the loop can be possible for both cases. For efficient operation of LHP, it is necessary to understand the behavior of the loop at different heat load, which will be presented in this study.

To explain the physics behind the operation, researchers are currently more interested in visualization of LHP. Neutron radiography has been used for visualization of liquid and vapor phase inside LHP (Cimbala et al., 2004). For visualization of flow, clear tubes have been used in vapor and liquid line and a transparent window was made in the compensation chamber of LHP (Wang and Nikanpour, 2007). To visualize the phase changes in the evaporator, a bore scope was utilized in the compensation chamber (d'Entremont and Ochterbeck, 2008). Infrared was employed to find the temperature distribution along LHP. To track the flow in the vapor and liquid line of LHP, infrared technique was also used (Launay, 2010). Also an experiment was conducted to visualize a stratified two-phase flow and film condensation in loop (Bartuli et al., 2013). The theoretical model without any physical observation of the processes is unable to provide any comprehensive picture of the system. Especially, for two-phase system, it is very important to investigate the behavior of the fluid inside the evaporator and condenser where the phase changes take place. Most of the structures of LHP are made from either copper or stainless steel or from other metallic component. These structures are not capable of providing any comprehensive visualization of system. For LHP, it is important to investigate the behavior of the fluid inside the evaporator and in condenser where the phase changes take place and other components of loop. But all visualization investigated earlier by others, focused on components based visualization of loop rather than the whole system. These experiments concentrated on visualization of one or two component of loop such as compensation or condensation chamber. But

*Corresponding author.Email: jpkizito@ncat.edu 
these experiments lack the explanation of what was happening in other components and did not show the operational transition from one component to another. In some cases, these individual component's results were lumped together to get the visualization of the systems. So there is a need to have a system which can visualize the complete process at one time. To remove these constraints, the present system can visualize the whole process in a single view frame and helps us to connect and linkup working fluid flow throughout all the components. The visualization process explained here will help us to understand the physical phenomenon such as two phase flow during startup, bubble formation and collapse in the condenser and compensation chamber during the LHP operation.

To meet the requirements mentioned above, a copper-water LHP with a flat evaporator and a flat condenser was designed and developed to evaluate and compare the thermal performance and startup process at different heat load. Also, main structure of LHP was fabricated inside acrylic plastic block to perform visual investigations on different components to describe the operational process at different stages of startup process.

\section{EXPERIMENTAL SETUP}

\subsection{Fabrication of wick structure}

A wick has been fabricated by sintering fine copper powder. The copper powder was purchased from Alfa Aesar, MA, USA and the powder was spherical in shape (approximately $10 \mu \mathrm{m}$ diameter). Fine powder was selected to minimize the pore size to develop high capillary pressure in wick to overcome the pressure drop at different components of the loop especially in the wick itself. The disc shape wick is $25.4 \mathrm{~mm}$ in diameter and $5 \mathrm{~mm}$ in thickness with $9-10$ micron mean pore diameter and $40 \%$ porous volume. The wick was sintered into a tube furnace under protective atmosphere to avoid oxidation during the sintering process. The complete sintering process used was originated from (Domínguez Espinosa, 2011)

\subsection{Experimental set-up}

The experimental setup is shown in Figure 1. Most of the structure of LHP is made from either copper or stainless steel and the operational process inside the loop cannot be observed. But in the current study, to visualize the processes, main components of LHP were fabricated inside an acrylic plastic block (Figure 2).

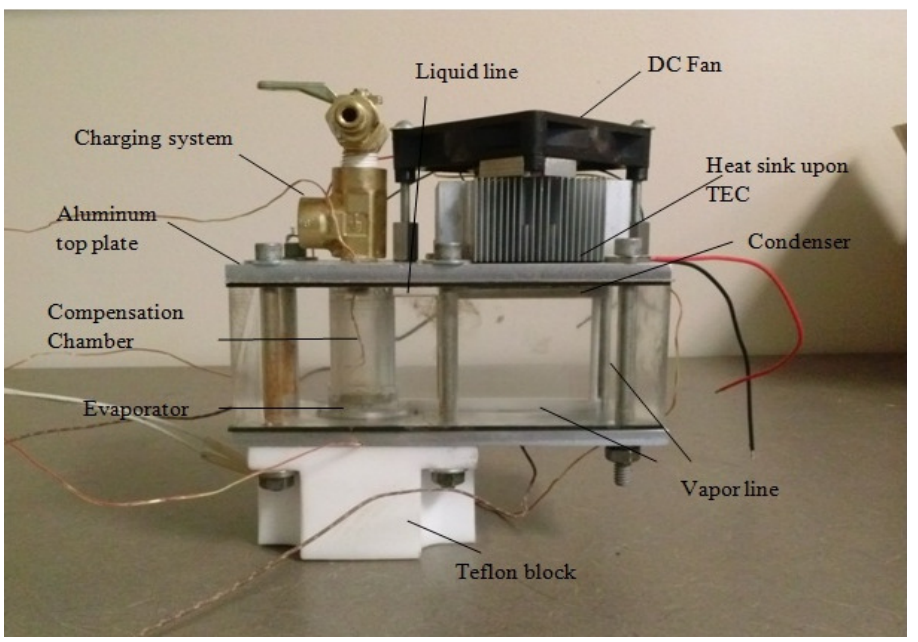

Fig. 1 Experimental set-up

Beside transparency, another advantage of the acrylic plastic was low heat loss from loop to surrounding environment. In contrast, heat loss from metallic body to environment is comparatively large and can affect the performance of the loop. The total dimension of the fabricated plastic block $(\mathrm{L} \times \mathrm{W} \times \mathrm{H})$ was $143 \times 80 \times 50 \mathrm{~mm}$ and the maximum temperature the plastic block can withstand is $140^{\circ} \mathrm{C}$. Two-aluminum plates of $6 \mathrm{~mm}$ thickness were used to cover the top and bottom of the plastic mold with proper insulation.

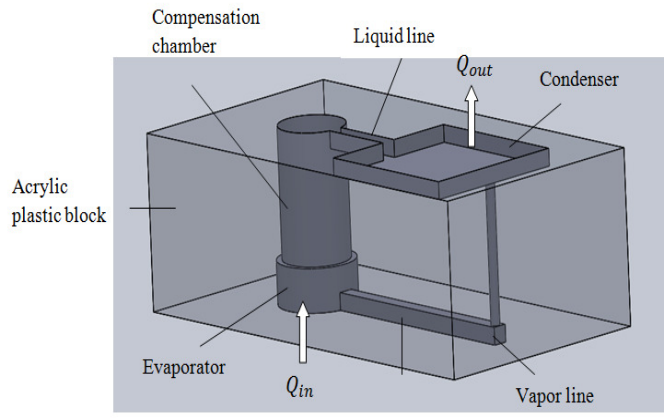

Fig. 2 Acrylic plastic structure of LHP

Table 1 presents dimensions of main components of LHP. A rectangular groove was formed in the acrylic mold to use as condenser.

Table 1 The main geometrical parameters of the LHP

\begin{tabular}{|l|c|}
\hline \multicolumn{1}{|c|}{ Components of LHP } & Dimensions $(\mathrm{mm})$ \\
\hline Diameter of wick & $25.4 \mathrm{~mm}$ \\
Thickness of wick & $5 \mathrm{~mm}$ \\
Evaporator diameter & $26.67 \mathrm{~mm}$ \\
Evaporator height & $12.5 \mathrm{~mm}$ \\
Compensation chamber diameter & $22.86 \mathrm{~mm}$ \\
Compensation chamber height & $38.5 \mathrm{~mm}$ \\
Rectangular vapor channel cross section area & $5 \times 5 \mathrm{~mm}$ \\
Rectangular vapor channel length & $70 \mathrm{~mm}$ \\
Diameter of cylindrical vapor line & $3 \mathrm{~mm}$ \\
Length of cylindrical vapor line & $40 \mathrm{~mm}$ \\
Rectangular liquid channel cross section area & $5 \times 5 \mathrm{~mm}$ \\
Rectangular liquid channel length & $30 \mathrm{~mm}$ \\
Condenser cross section area & $50 \times 50 \mathrm{~mm}^{2}$ \\
Condenser depth & $5 \mathrm{~mm}$ \\
\hline
\end{tabular}

The condensation process was achieved by using a Thermo Eclectic Cooler (TEC) on the top of aluminum plate. Cooling can be controlled more accurately by TEC than conventional air or liquid cooling systems. Thermoelectric cooling uses the Peltier effect between the junctions of two different types of materials. A Peltier cooler transfers heat from one side of the device to the other, with consumption of electrical energy. Cooling can be controlled very accurately because of the electric controlling of the cooling system. Table 2 shows specification of a TEC with $\mathrm{L} \times \mathrm{W} \times \mathrm{H}$ of $50 \times 50 \times 3.2 \mathrm{~mm}$ respectively.

Table 2 Specification of TEC

\begin{tabular}{|c|c|}
\hline TEC parameters & Value \\
\hline$I_{\max }(\mathrm{amp})$ & 15.5 \\
$Q_{\max }($ watt $)$ & 225 \\
$V_{\max }($ volt $)$ & 24 \\
$D T_{\max }\left({ }^{\circ} \mathrm{C}\right)$ & 64 \\
$T_{\max }\left({ }^{\circ} \mathrm{C}\right)$ & 125 \\
\hline
\end{tabular}

Cold face of TEC is connected to the condenser. The heat from the hot face of TEC is removed by a heat sink of Aluminum fin. The dimension of heat sink is $42 \times 49 \times 40 \mathrm{~mm}$. On the top of the heat sink, a brushless DC electric fan is used to remove heat from heat sink to 
environment. The heat sink and fan assembly has capability to remove 125 watt thermal design power. Water was used as working fluid due to high surface tension and good compatibility with wick material.

Heat to the evaporator is provided by a cooper block holding the heater. The diameter of cylinder heater block was $31.75 \mathrm{~mm}$ and the length was $38.1 \mathrm{~mm}$. To accommodate the heater cartridge, a $6.35 \mathrm{~mm}$ hole was made in the heater block. A high density 150 watt cartridge heater was inserted into the block (Figure 3). To minimize the heat loss from heater to the surrounding, heater block was insulated by low thermal conductive Teflon ${ }^{\circledR}$ PTFE resins. Teflon is chemical resistance and can operate in high temperature (up to $500^{\circ} \mathrm{F}$ ).

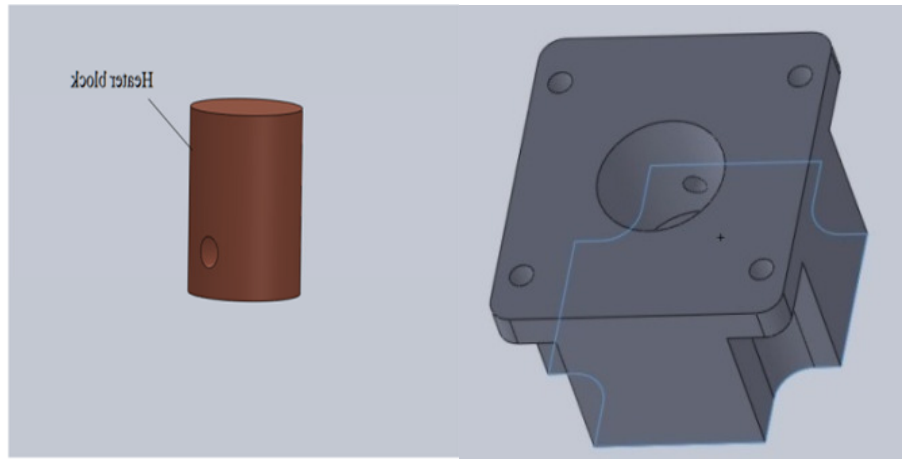

(a)

(b)

Fig. 3 (a) Copper heater block (b) Teflon block

Two high temperature gaskets were used for insulation and to prevent any leakage from LHP to surrounding. Packing was also used around the circumference of the wick to prevent any internal leaks of vapor to the compensation chamber and to minimize heat conduction from the evaporator sidewalls to the wick structure. To accumulate and remove vapor, an aluminum channel was used under the wick in the evaporator. The vapor removal channel has two main functions. The fins of grooves work as heat conductor between heat source and the wick and remove vapor to the vapor line. Surface contact between the wick and vapor channel was checked to ensure proper contact between them. A charging system was designed for charging working fluid in the loop. A three-way valve was attached upon the top plate of LHP. One port of the three-way valve was connected to a vacuum pump and the other port was connected to the liquid charging cylinder. The third port was connected to the compensation chamber of loop. Vacuum pump was used to evacuate air from loop before charging the working fluid. Detail of the experimental setup can be found in (Hossain and Kizito, 2015).

\section{TESTING PROCEDURE}

Temperature was measured by using K-Type thermocouples shown in Figure 4. Six thermocouples were used to read the temperature at different components in the system. One thermocouple was connected to the outer side of the Teflon block to measure the Teflon block's temperature. All the thermocouples were directly connected to IOtech 6000 series DAQ data acquisition system. The data acquisition system collects the data after every $0.5 \mathrm{sec}$ and display the data on computer. Error in temperature measurement by $\mathrm{K}$ type thermocouples is $\pm 0.1{ }^{\circ} \mathrm{C}$. Power to the heater block was provided by the Agilent 6030A voltage supply (Agilent Technologies, 5301 Stevens Creek Blvd, CA 95051, USA). At each voltage, the corresponding current is recorded and the power output is determined. Uncertainty in the power measurement is \pm 0.2 percentage.

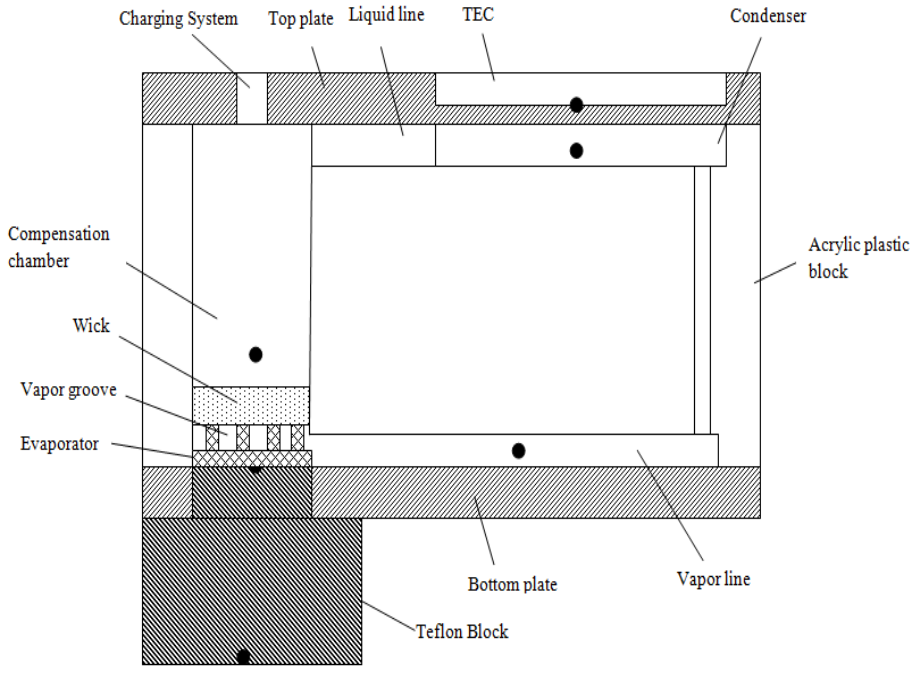

Fig. 4 Location of thermocouples inside the LHP (Black dots)

\section{RESULT AND DISCUSSIONS}

\subsection{Startup process}

Fig. 5 shows the startup process for 20 -watt heat load. At low heat input, heat leakage to the compensation chamber and to surrounding environment was comparatively large and it took several minutes to start up the system. The generation of vapor bubbles was irregular and small in number at the startup of the operation. High oscillation in temperature can be observed in the evaporator at approximately 25 minutes. The reason for large oscillation was the alternating vaporization and flooding in the porous wick which causes instability of the meniscus in the wick. At the beginning of the evaporation, the meniscus in the pores of the evaporator wick became unstable which caused high oscillation. The meniscus becomes stable later and the temperature rises steadily. Similarly, oscillation in temperature was also observed in compensation chamber due to inconsistent return of condensed liquid from condenser.

In addition, the vapor line temperature was low due to low vapor generation and vapor bubbles collapsed in vapor line due to presence of excess liquid. During the startup process, the vapor temperature kept rising at a steady rate. For TEC and condenser, temperature remained almost same and kept below $20^{\circ} \mathrm{C}$.

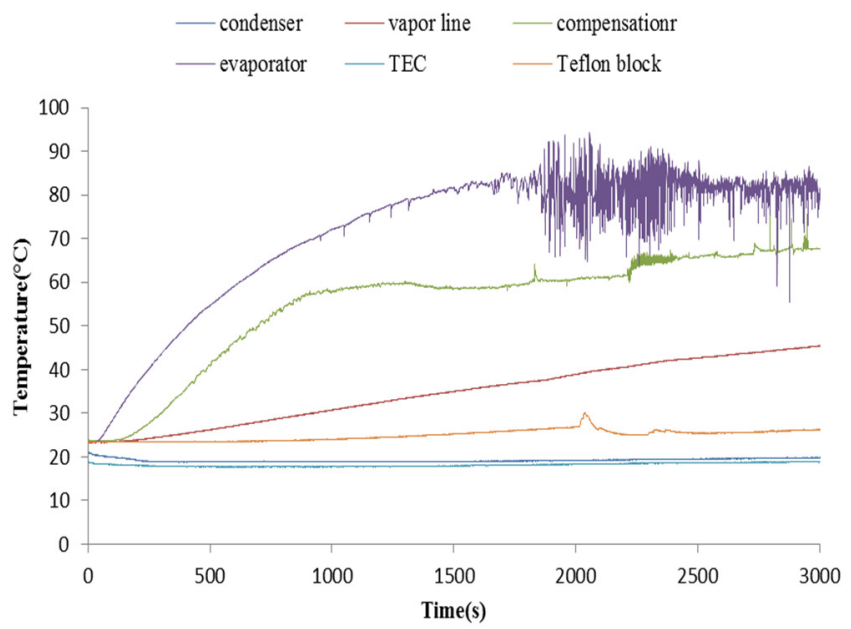

Fig. 5 LHP startup process with 20-watt heat load 
Figure 6 shows the effects of 60 -watt heat load in the evaporator. The temperatures of evaporator, compensation chamber and vapor outlet ascended very quickly at the beginning of the startup. Small temperature fluctuation in compensation chamber was also observed due to the collapses of the bubble which is explained through visualization process later. Vapor outlet temperature increased in fast rate with frequent small amplitude oscillation. Some spikes were also observed in condenser temperature. Collapse of vapor bubble in the condenser causes those oscillations. After the condenser was filled with liquid, the high velocity incoming vapor, created oscillation in condensed fluid. During the entire operation, TEC temperature increased steadily at very slow rate.

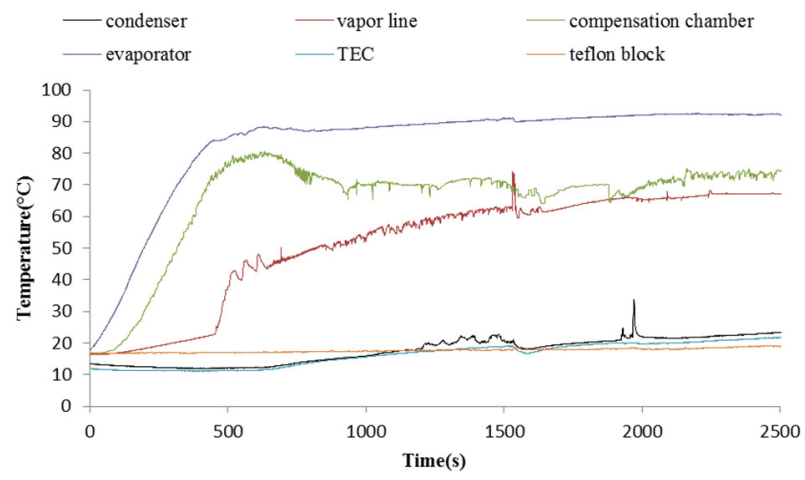

Fig. 6 LHP startup process with 60 -watt heating power

Response of the system at power input of 100 watt can be viewed at Figure 7. High oscillation at the evaporator temperature can be observed at the beginning of operation and then the temperature increased steadily. The vapor line temperature increased very quickly and keeps climbing due to quick and high vapor generation which also increases the condenser temperature after 16 minutes of start of operation. Though there was some oscillation in compensation chamber temperature but the profile remains almost stable.

$$
\begin{array}{ccc}
\text { - condenser } & \text { - vapor line } & \text { compensation } \\
\text { evaporator } & \text { TEC } & \text { teflon block }
\end{array}
$$

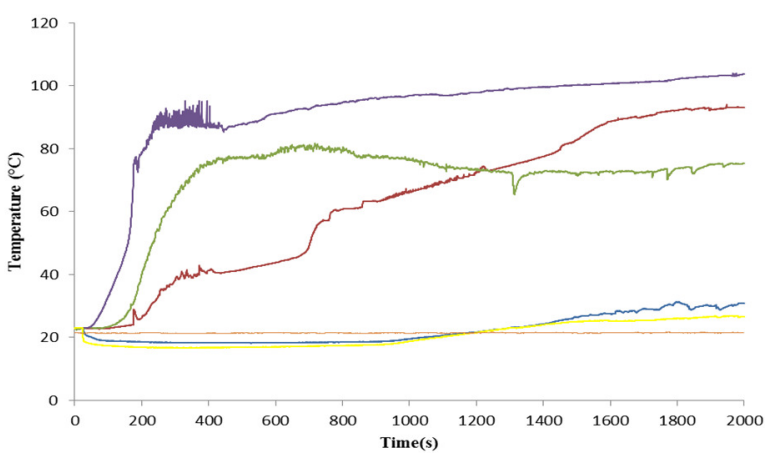

Fig. 7 LHP startup process at heat load of 100 watt

\subsection{Evaporator thermal resistance $\&$ heat transfer coefficient}

Evaporator is the most significant component of the LHP and can determine the overall performance of the device. One of the important factors for determining system performance is evaporator thermal resistance. Evaporator thermal resistance is the resistance encountered at the evaporator. Evaporator thermal resistance is defined as follows

$R_{t h}=\frac{T_{e}-T_{v}}{Q}$

where $T_{e}$ is the temperature in evaporator, $T_{v}$ is the temperature in vapor line and $Q$ is the applied thermal load. The designed LHP was capable of cooling efficiently high heat fluxes without any concern in the performance. The efficiency of heat exchange system can be determined by the heat transfer coefficient.

$\mathrm{h}=\frac{\mathrm{Q}}{\mathrm{A}_{\mathrm{e}}\left(\mathrm{T}_{\mathrm{e}}-T_{v}\right)}$

where $A_{\mathrm{e}}$ is the active heated area for the applied load, $T_{e}$ is the evaporator temperature, $T_{v}$ is the temperature in vapor line and $Q$ is the applied thermal load. For an efficient thermal system, thermal resistance should decreases with the increase of heat load. It is evident from the Figure 8, evaporator thermal resistance decreased with increased of heat load.

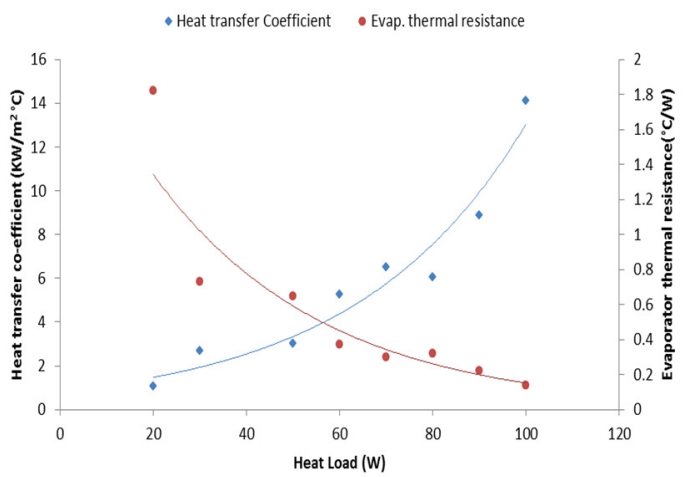

Fig. 8 Evaporator heat transfer coefficient vs. heat load

The evaporator thermal resistance was low for heat load range of 60 watt to 100 watt. This range was the efficient region where the system is stable. The resistance was as low as $0.14^{\circ} \mathrm{C} / W$ at the heat load of 100 watt. Figure 8 also illustrate heat transfer coefficient at different heat loads. Maximum heat transfer coefficient in the evaporator was $14.11 \mathrm{KW} / \mathrm{m}^{2}{ }^{\circ} \mathrm{C}$ for 100 watt. The Figure 8 clearly indicates that high values of the heat transfer coefficient can be achieved at relatively high heat loads. The minimum value of heat transfer coefficient was found $1.08 \mathrm{KW} / \mathrm{m}^{2 \circ} \mathrm{C}$ for 20 watt.

\subsection{Thermal behavior of condenser}

Heat transfer efficiency depends on the performance of condenser. In present study, TEC has been utilized for condensation process.

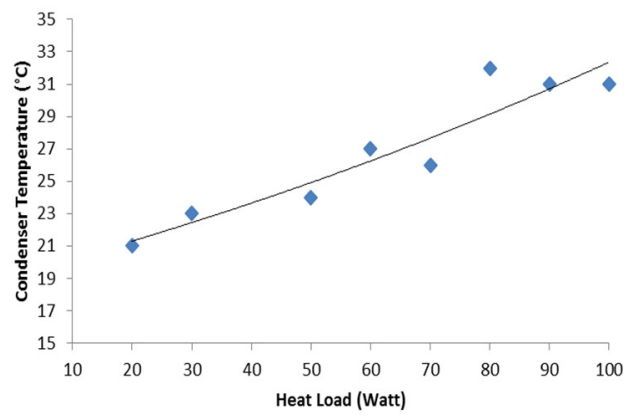

Fig. 9 Condenser temperature at different heat load after operating LHP for 30 minutes

The temperature of the condenser at different power input after certain period of time is shown in Figure 9. It is the temperature recorded after operating the LHP for 30 minutes from startup at different heat loads. The figure illustrates that condenser temperature increased steadily with increase heat load. The maximum condenser temperature at the end of the operation was approximately $32^{\circ} \mathrm{C}$. For high heat load, vapor generates very quickly and enters the condenser with high velocity. When the condenser is filled up, it cannot immediately condense the incoming vapor directly into liquid therefore two phases exists in condenser. 


\subsection{Transient behavior of evaporator}

Evaporator contains the wick which separate the two phase of the fluid. The evaporator dictates the startup process and the steady state condition. Figure 10 illustrates the temperature profile of the evaporator at different heat loads. High oscillation of the temperature can be seen at low heat load of 20 watt. The rate of temperature rise increased with the rise in power input. It needed longer time to start the vapor generation for the low heat input of 20 watt. In contrast, the system reaches the vapor generation temperature quickly for the high heat load. For this case, the start of vapor generation was very quick and it reached the steady state temperature of approximate $100^{\circ} \mathrm{C}$ for the heat load of 90 and 100 watt. For high heat load, high oscillation in temperature can be found at the beginning of operation due to faster vapor generation and instability of meniscus in the beginning of startup.

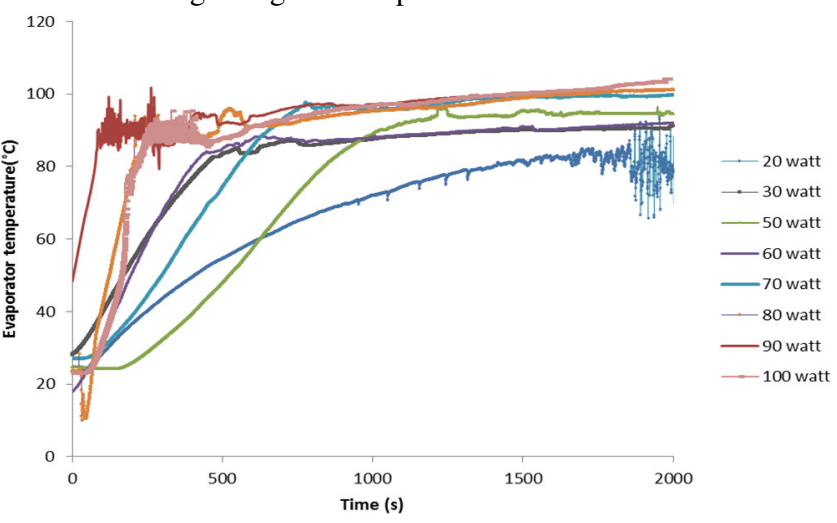

Fig. 10 Evaporator temperature at different heat loads

A temperature jump can be observed in evaporator and vapor temperature after 100 watt heat load and theses temperatures kept rising quickly and made the system unstable. But for heat load till 100 watt, the system remained steady with the progress of time. It can be noticed that the slope of the evaporator temperature curve increases with the increase of heat load, which represents faster evaporation process.

\subsection{Visualization of operation in LHP}

The experimental setup consisted of a high-speed camera attached to a zoom lens with a magnification such that the transparent acrylic plastic mold was the visible field of view. High-speed camera (Photron USA, Inc.,San Diego) was used to capture front-view images of different component of loop at 5000 frames per second (fps).

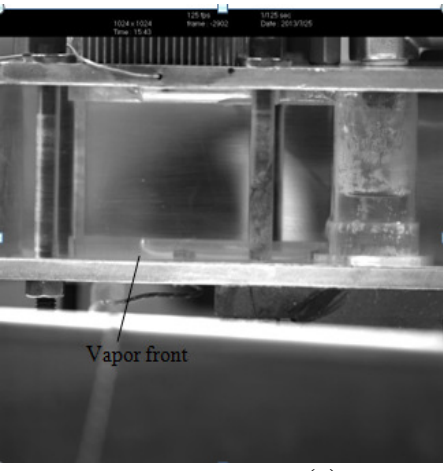

(a)

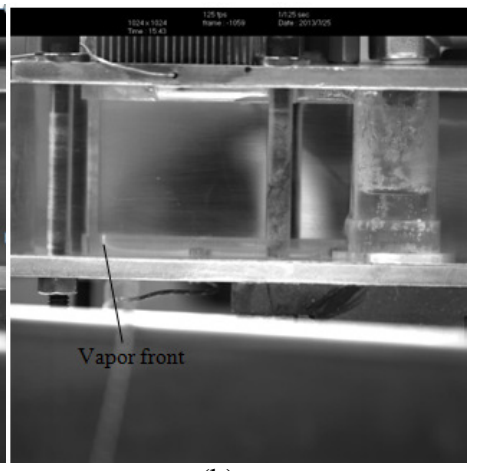

(b)
Fig. 11 Advancement of vapor in the vapor line during startup

In a typical experiment, a few video frames of the sample were obtained with normal lighting for calibration before starting the experiment.
Image-Pro Plus 5.0 software was used to analyze the images of visualization.

Starting process of LHP can be divided into several stages (Jun and Woei, 2011). At the beginning of startup, generated vapor drives out the liquid out of vapor groove and vapor line. During beginning of the startup, the meniscus is not stable in wick and causes high temperature oscillation in evaporator temperature which can be confirmed through the startup temperature plot discussed earlier. Generated vapor displaced the excess liquid from vapor groove and vapor line. Forward movement of vapor front is shown in Figure 11.

After the vapor groove and vapor line is free of liquid, the generated vapor in the evaporator directly comes to the condenser. As soon as the vapor comes to the condenser, condensation takes place and the vapor turn into liquid. After the condenser is filled up with the liquid, the liquid boundary fluctuated in a wavy manner due to incoming high velocity vapor in the film liquid. The oscillations were too small to influence the temperature distribution at the condensation surface.

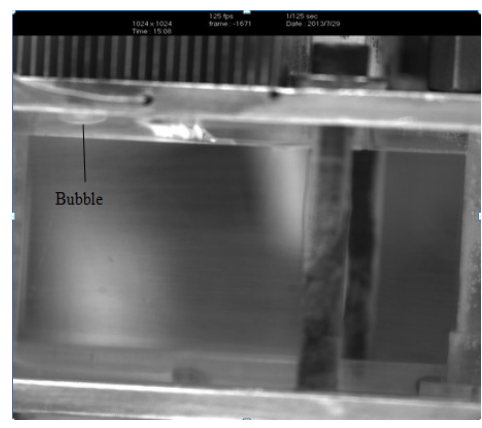

Fig. 12 Bubble in the condenser

During condensation, bubble forms inside the condenser and collapses (Figure 12) and collapsing of vapor bubbles also creates pressure waves and temperature oscillation which have been discussed earlier in condenser temperature plot. The formation of bubble increased with heat load. The condensed liquid returns into the compensation chamber. The rate of return of condensed liquid was inconsistent at the beginning of startup operation. During the operation, heat leaks from evaporator to the compensation chamber and the cold liquid from condenser balances the heat leakage to the compensation chamber.

Formation of bubble was observed inside the compensation chamber along with the wick and on the surfaces of the chamber with the rise of temperature. Rate of bubble formation in the compensation chamber increased with increase in heat load. The collapses of these bubbles cause oscillation in evaporator temperature. With high heat load, the top surface of the wick was covered by bubbles and constrained the supply of the liquid in the wick and caused the dry out of the wick. The formation of bubbles inside the evaporator is shown in Figure 13.

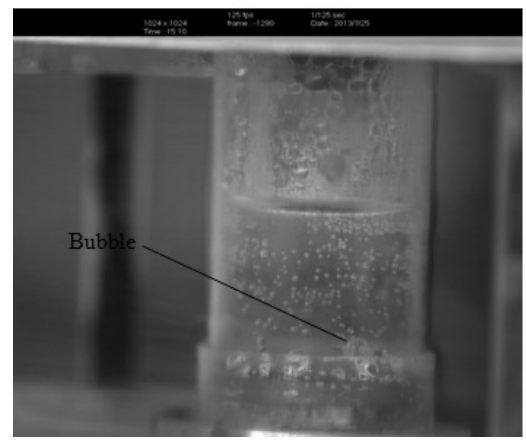

Fig. 13 Formation of bubbles in compensation chamber 


\section{CONCLUSIONS}

A flat loop heat pipe was fabricated with a copper wick of $25.4 \mathrm{~mm}$ diameter and $5 \mathrm{~mm}$ thickness. A flat evaporator LHP with copper wick has been studied for different heat load. Thermal resistance and heat transfer co-efficient were measured and compared for the complete loop at various heat loads. Images were taken by the high-speed camera to explain operational performance at different stages of the startup process and evaluate the component performance in loop. The outcome of the study can be concluded as follows:

For a disc shape wick, LHP was able to handle 100-watt heat load with the evaporator thermal resistance of $0.14^{\circ} \mathrm{C} / W$ and heat transfer coefficient of $14.114 \mathrm{~W} / \mathrm{m}^{2}{ }^{\circ} \mathrm{C}$. The system is compact and can be used effectively for thermal cooling.

High oscillation in evaporator temperature was observed for low heat load. The vapor generation needed longer times for low heat load and for this reason, these oscillations in evaporator temperature did not begin immediately after startup. In contrast, for high heat loads vapor generated quickly and the oscillation in evaporator temperature was seen at the earlier stage of startup. Some fluctuation in temperature was also observed in compensation chamber, vapor line and condenser temperatures. Reasons behind these temperature oscillations were explained with visual evidence.

A high-speed camera was used to visualize the operational behavior of LHP on a single frame. Displacement of excess liquid from vapor line was visualized during starting process. Formations of bubbles inside the condenser and on the wick of compensation chamber were detected. These phenomena are important to understand the physical behavior of loop at different stages of operation.

\section{ACKNOWLEDGEMENTS}

This research was funded by the Department of Defense through WrightPatterson Air Force Research Laboratory Dayton, Ohio via a sub contract from United Technologies Corporation FA8650-08-D-2806 Task Order 0004, Subcontract Agreement\#: 11-S590-0004-02-C18. The authors express their sincere appreciation for all of the support provided.

\section{NOMENCLATURE}

$\begin{array}{ll}R & \text { thermal resistance }\left({ }^{\circ} \mathrm{C} / W\right) \\ T & \text { temperature }\left({ }^{\circ} \mathrm{C}\right) \\ Q & \text { heat load }(\mathrm{W}) \\ h & \text { heat transfer coefficient }\left(\mathrm{KW} / \mathrm{m}^{2}{ }^{\circ} \mathrm{C}\right) \\ A & \text { Area }\left(\mathrm{m}^{2}\right) \\ \text { Subscripts } & \\ e & \text { evaporator } \\ v & \text { vapor line } \\ t h & \text { thermal }\end{array}$

\section{REFERENCES}

Bartuli, E., Vershinin, S., Maydanik, Y., 2013, "Visual and Instrumental Investigations of a Copper-Water Loop Heat Pipe," International Journal of Heat and Mass Transfer, 61, 35-40. https://doi.org/10.1016/j.ijheatmasstransfer.2013.01.074

Bienert W.B., Nikitkin M.N., 1999, "Thermal Control With Low Power Miniature Loop Heat Pipes," 29th Int. Conf. Environ. Syst., Denver, CO. https://doi.org/10.4271/1999-01-2008

Cimbala, J.M., Brenizer, J.S., Chuang, A.P.-Y., Hanna, S., Thomas Conroy, C., El-Ganayni, A., Riley, D.R., 2004, "Study of a Loop Heat Pipe Using Neutron Radiography," Applied radiation and isotopes, 61, 701-705.

https://doi.org/10.1016/j.apradiso.2004.03.104

d'Entremont, B., Ochterbeck, J., 2008, "Investigation of Loop Heat Pipe Startup Using Liquid Core Visualization," ASME 2008 Heat Transfer
Summer Conference collocated with the Fluids Engineering, Energy Sustainability Conferences, Jacsonville, FL. https://doi.org/10.1115/ht2008-56387

Dominguez Espinosa, F.A., 2011, "Effect of Fabrication Parameters on the Thermophysical Properties of Sintered Wicks," Doctoral dissertation, Massachusetts Institute of Technology

Gai, D., Liu, Z., Liu, W., Yang, J., 2009, "Operational Characteristics of Miniature Loop Heat Pipe With Flat Evaporator," Heat and mass transfer, 46, 267-275.

https://doi.org/10.1007/s00231-009-0563-0

Joung, W., Yu, T., Lee, J., 2008, "Experimental Study on the Loop Heat Pipe With a Planar Bifacial Wick Structure," International Journal of Heat and Mass Transfer, 51, 1573-1581.

https://doi.org/10.1016/j.ijheatmasstransfer.2007.07.048

Jun, X., Woei, S., 2011, "Thermal Performances of Loop Heat Pipe with Hybrid Wick Structures in Evaporator," 10th IHPS, Taipei, Taiwan.

Kim, K.-S., Won, M.-H., Kim, J.-W., Back, B.-J., 2003, "Heat Pipe Cooling Technology for Desktop PC CPU," Applied thermal engineering, 23, 1137-1144. https://doi.org/10.1016/s1359-4311(03)00044-9

Hossain, M.M., Kizito, J.P., 2015, "Experimental Study of Thermal Performance of a Flat Loop Heat Pipe," Frontiers in Heat Pipes (FHP), 6(1).

https://doi.org/10.5098/fhp.6.5

Launay, S., and Mekni, N., 2010, "Specifically Designed Loop Heat Pipe for Quantitative Characterization," 15th International Heat Pipe Conference, Clemson, USA.

Launay, S., Sartre, V., Bonjour, J., 2007, "Parametric Analysis of Loop Heat Pipe Operation: A Literature Review," International Journal of Thermal Sciences, 46, 621-636. https://doi.org/10.1016/j.ijthermalsci.2006.11.007

Liu, Z., Gai, D., Li, H., Liu, W., Yang, J., Liu, M., 2011, "Investigation of Impact of Different Working Fluids on The Operational Characteristics of Miniature LHP with Flat Evaporator," Applied Thermal Engineering, 31, 3387-3392.

https://doi.org/10.1016/j.applthermaleng.2011.06.023

Maidanik, Y.F., Solodovnik, N., Fershtater, Y.G., 1995, "Investigation of Dynamic and Stationary Characteristics of a Loop Heat Pipe," IX International Heat Pipe Conference, Albuquerque, New Mexico.

Maydanik, Y.F., Vershinin, S.V., Korukov, M.A., Ochterbeck, J.M., 2005, "Miniature Loop Heat Pipes-A Promising Means For Cooling Electronics," Components and Packaging Technologies, IEEE Transactions on, 28, 290-296.

https://doi.org/10.1109/itherm.2004.1318253

Sauciuc, I., Prasher, R., Chang, J.-Y., Erturk, H., Chrysler, G., Chiu, C.P., Mahajan, R., 2005, "Thermal Performance and Key Challenges for Future CPU Cooling Technologies," ASME Conference Proceedings, 353-364.

https://doi.org/10.1115/ipack2005-73242

Singh, R., Akbarzadeh, A., Dixon, C., Mochizuki, M., Riehl, R.R., 2007, "Miniature Loop Heat Pipe with Flat Evaporator for Cooling Computer CPU," Components and Packaging Technologies, IEEE Transactions, 30, 42-49.

https://doi.org/10.1109/tcapt.2007.892066

Wang, G., Nikanpour, D., 2007, "Visual Observations of Flow and Phase Phenomena in Loop Heat Pipes", AIP Conference Proceedings, p. 291. https://doi.org/10.1063/1.2747444 